\title{
LIFI BASED INDOOR NAVIGATION SYSTEM FOR THE VISUALLY IMPAIRED PEOPLE
}

\author{
Dr. S. Mary Praveena, Teena Sree .G, Winonah Rajendran, Pavithra .P \\ Department of ECE \\ Sri Ramakrishna Institute of Technology, \\ Coimbatore, Tamil Nadu, India
}

\begin{abstract}
Localization and navigation system are practically viable and can easily be used but are not commonly used in real time. According to world health organization there were 285 million visually impaired people and 39 million were blind. Various technologies like RFID, ZigBee have been suggested but they all possess serious drawbacks and hence are not practically used. In this paper an indoor navigation and information system that is easy to implement and use has been proposed, because it uses visible light communication (VLC), which is an ideal technology for an application like this. Visually impaired people confront unique challenges in their day-to-day life when navigating in unfamiliar public locations. The proposed system focuses on designing a device for visually impaired people that is comfortable, user friendly and also helps travelling independently. A VLC navigation system is useful for assisting blind people. This system aims to provide location information in the absence of explicit instructions and can be a supporting method for users who travel in buildings. The transmitter section contains LED lights emitting visible lights that contain positional information to provide direction to the user. In the receiver section the embedded system calculates the optimal path to a designation and speaks to the person through a headphone or speaker. In addition to the basic navigation capabilities, the proposed system also aims to provide the user certain information on the nearby points-of-interest (POI) and accessibility issues such as stairs, drain, etc. The voice or data is used as an output result of transmission of LED lights.
\end{abstract}

Keywords: Light Fidelity (Li-Fi), Wi-Fi, Light Emitting Diode, Visible Light Communication (VLC), wireless, navigation, security.

\section{INTRODUCTION}

The indoor navigation system can be used in house, hospitals and in any location where they live. The system consists of a transmitter section which is indoor and receiver section which is with the blind person. Whenever the Li-Fi receiver receives the data from transmitter section, it gives voice output using voice recorder circuit that is in the corresponding rooms [1]. The entire function is managed by a controller. The Li-Fi technology can transfer data through the LEDs by the visible light that they emit. It is a high speed and low cost wireless communication systems which provides high security, large bandwidths and also low cost. Li-Fi generally uses household LEDs (Light Emitting Diode) for data transferring. Li-Fi is currently acquiring a great deal of interest because of its efficiency. As a large number of people have started using Wi-Fi in such cases the Li-Fi will overcome such problems. Light fidelity is a bidirectional, fully networked wireless communication technology like WiFi.[2] Most indoor locations would have sufficient amount of light resources. It also provides additional security since $\mathrm{Li}-\mathrm{Fi}$ cannot penetrate through walls. Indoor navigation is indispensable for the visually impaired people, so such a navigation system for the visually impaired has been proposed.

\section{OVERVIEW OF VISIBLE LIGHT COMMUNICATION}

Visible Light Communication (VLC) has gained great interest in the last decade due to the rapid developments in Light Emitting Diodes (LEDs) fabrication. [3] Efficiency, durability and long life span of LEDs make them a promising residential lighting equipment as well as an alternative cheap and fast data transfer equipment.

Benefits of Visible Light Communication

- High security

- Simple deployment

- Low implementation cost

- No radio-frequency interference

- License-free operation

Its abundance is the main advantage over other communication system. Light sources are available everywhere and can be more efficiently used by increasing its simultaneous functionality by transmitting data in addition to lighting an area. On resorts, company buildings and grocery 


\section{International Journal of Engineering Applied Sciences and Technology, 2020 \\ Vol. 4, Issue 9, ISSN No. 2455-2143, Pages 372-376 \\ Published Online January 2020 in IJEAST (http://www.ijeast.com)}

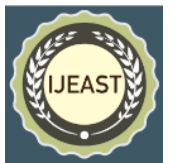

stores, will have on for at least the duration of hours of operation, of which could be used for VLC. VLC is mostly used indoors and transmitted light consequently does not leave the room when the doors are closed and the curtains drawn, because light cannot penetrate solid objects such as walls or furniture. [4]Therefore, it is hard to eavesdrop on a visible light based conversation, which makes VLC a safe technology if the sender intends to transmit confidential data.

\section{PROPOSED MODEL}

People with visual disabilities, either partially or totally blind, are often challenged by places that are not designed or their special condition. Examples of these are bus and train terminals, hospitals and shopping malls. Several "everyday" objects that are present in most built environments become real obstacles for blind people, even putting at risk their physical integrity. Simple objects such as chairs, tables and stairs, hinder their movements and can often cause serious accidents because of their disability to see the objects. This Li-Fi technology helps the visually impaired to move within indoor environments. The main objective of the system is to provide, in real -time, useful navigation information that enables the users to make appropriate and timely decisions on which route to follow in an indoor space without trouble. Indoor navigation is convenient and comfort to everyone and it is especially indispensable for the visually impaired. Li-Fi makes use of a free, unlicensed spectrum and is not affected by RF noise. [5]Furthermore, since Li-Fi cannot penetrate through wall, most indoor locations would have an enough amount of light sources and provide surplus security. The concerns of the lack of radio frequency bandwidth may be ruled out by Li-Fi and high data transmission rates of up to $15 \mathrm{Gbps}$ can be attained. With the increasing use of Wi-Fi, the existing radio frequency is getting clogged deliberately and simultaneously, there are an increasing number of people who want to connect to the internet. LI-FI uses the Visible Light Communication, is a data communications medium which uses visible light and will contribute the visually impaired people for the navigation and helps them to easily travel autonomously at indoor places using this system.

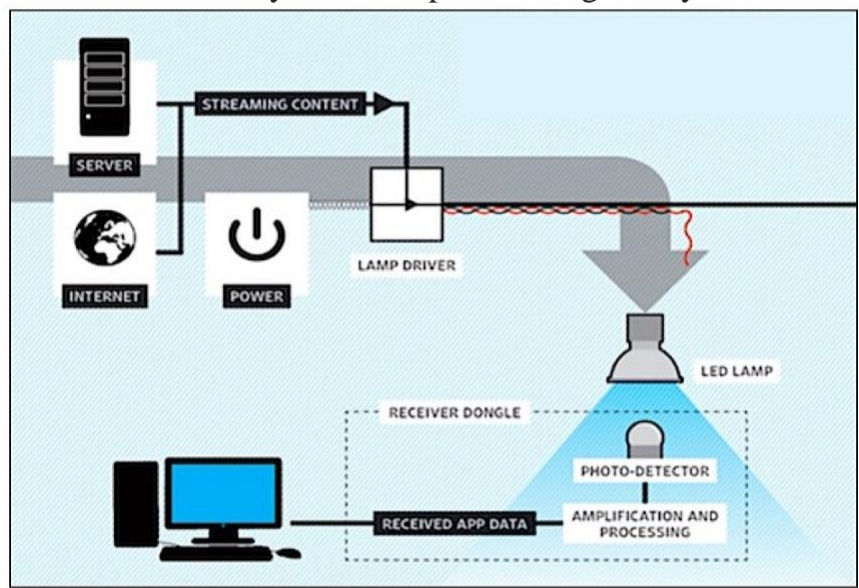

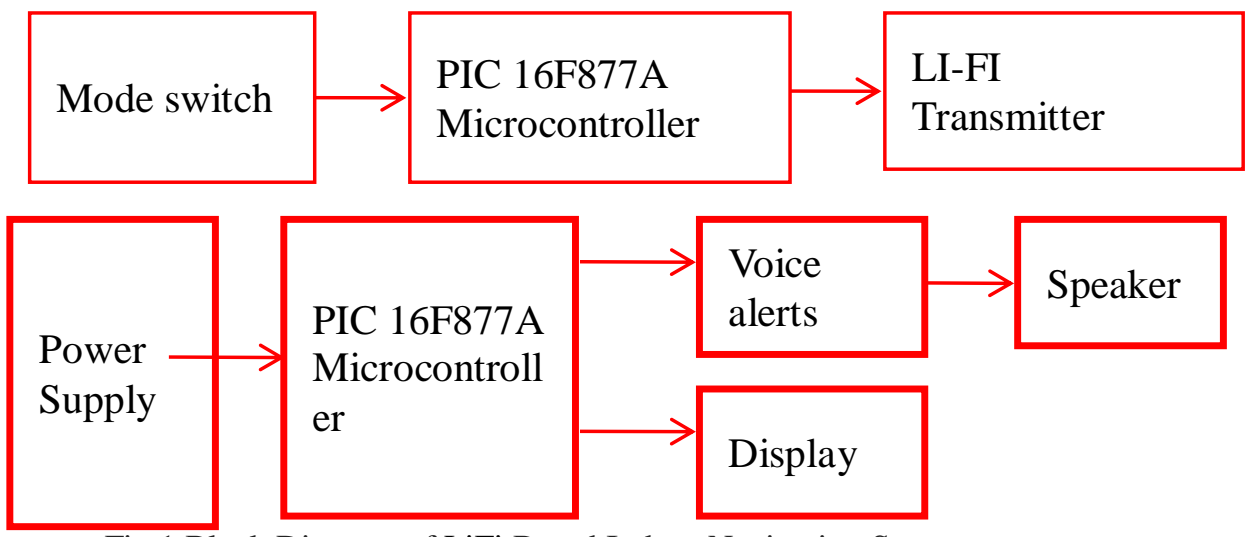

Fig 1.Block Diagram of LiFi Based Indoor Navigation System

From Figure 1 we can see that the transmitter side will transmit the data and it is connected to arrays of LED through which data is transferred. The general idea is to modulate the light intensity of the LED i.e. the intensity of the light corresponds to the symbol transmitted. This data will be received by the receiving side $(\mathrm{Rx})$ side. Receiver (Rx) The receiver side will receive the data that is transmitted through the led panel [6]. This led can be displayed to the HyperTerminal of the Pc by connecting a serial part Source of light used to communicate between devices using light to transmit data and position. In its present state only LED lamps can be used for the transmission of visible light.

PIC Development Board is a device that proposed to make the progress of developing and debugging of various designs encompassing Microcontrollers from Microchip smoother. It was designed as to facilitate (16F/18F 40PIN DIP) On-board Programmer for PIC Microcontroller through ISP on Universal Serial port. It integrates on board USART, LEDs, keypads, 3 ADC inputs and LCD Display to create a stand- 


\section{International Journal of Engineering Applied Sciences and Technology, 2020 \\ Vol. 4, Issue 9, ISSN No. 2455-2143, Pages 372-376 \\ Published Online January 2020 in IJEAST (http://www.ijeast.com)}

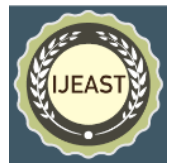

alone versatile test platform. User can easily engage in development in this platform, or use it as reference to application development.[10] The PIC microcontroller PIC16F877A is one of the most renowned microcontrollers in the industry. PIC16F877A finds its applications in a huge number of devices. It is used in remote sensors, security and safety devices, home automation and in many industrial instruments. An EEPROM is also featured in it which makes it possible to store some of the information permanently like transmitter codes and receiver frequencies and some other related data. The cost of this controller is low and its handling is also easy. This $12 \mathrm{~V} 2 \mathrm{~A}$ Power Adapter is a high quality power supply manufactured specifically for electronics.[7] These are switch mode power supplies which means the output is regulated to $12 \mathrm{~V}$ and the capable output current is much higher $(2000 \mathrm{~mA})$.

Jumper wire is an electrical wire, or group of them in a cable, with a connector or pin at each end (or sometimes without them - simply "tinned"), which is normally used to interconnect the components of a breadboard or other prototype or test circuit, internally or with other equipment or components, without soldering.[9] Vibration motor is a compact size coreless DC motor used to informs the users of receiving the signal by vibrating, no sound.[8]. The main features of vibration motor is the magnet coreless DC motor are permanent, which means it will always have its magnetic properties. Figure 2 and Figure 3 shows the transmitter and receiver circuit boards.

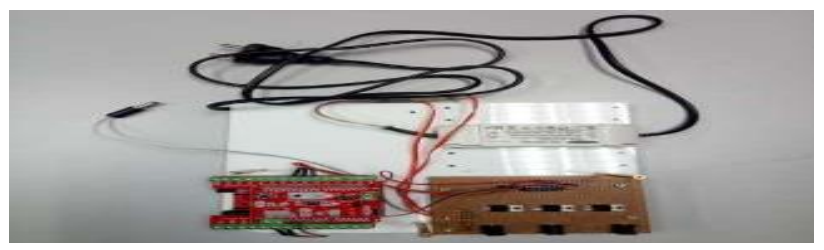

Figure 2: Transmitter circuit board

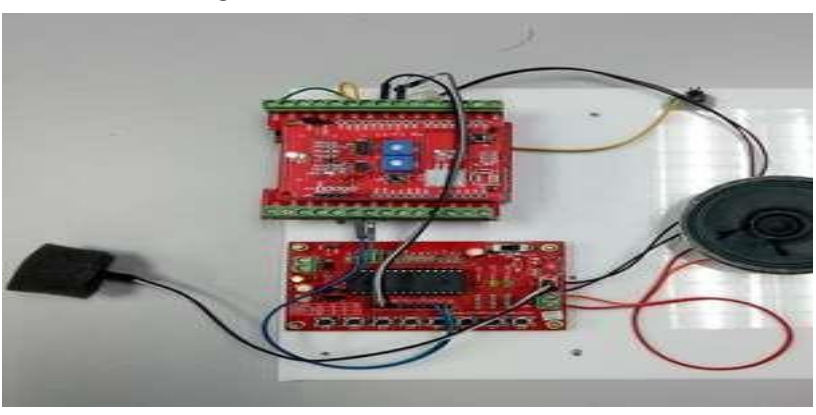

Figure 3: Receiver Circuit Board

\section{Voice Playback and Recorder Kit}

It provides high quality recording and playback with 11 Minutes audio at $8 \mathrm{Khz}$ Sampling rate with 16 bit resolution. [11]The aPR33A series C2.x is specially designed for simple key trigger, user can record and playback the message averagely for $1,2,4$ or 8 voice message(s) by switch, It is suitable in simple interface or need to limit the length of single message[12].

\section{Recording Procedures:}

- Avoid connecting smps or any ac to dc conversion voltage source.

- Use a $5 \mathrm{~V}$ battery while recording.

- Avoid blank space in wave file.

- It is always better to record from PC or mobile speaker out jack terminal.

- Recorded volume level should moderate.

- Use audio equalizer from PC or mobile to fine tune as per your desired output.

\section{FLOWCHART}

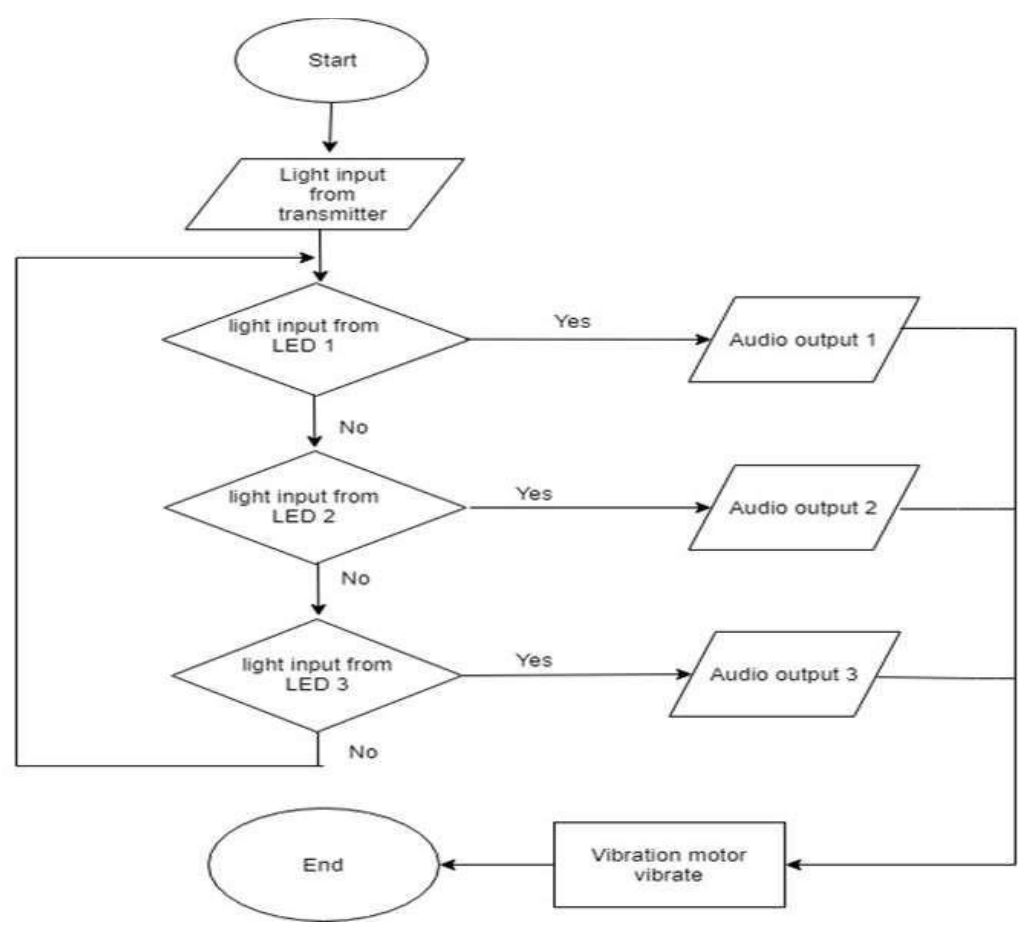

Figure 4: Flowchart of LED based navigation system: Aid for blind and visual impairment people

\section{RESULT AND DISCUSSION}

This paper explains and shows the final results that have been obtained from this paper. It will show the screen capture of the important steps that need to be taken when completing this paper. Figure 5 shows the complete design of this paper. This paper will start by inserting transmitter and receiver code to the circuit board. This step can be done by using Arduino IDE software. Results obtained from this paper is signal from transmitter circuit can be transmitted from transmitter circuit to receiver circuit. Every LED have own data to transmit and it is different from the others. The 


\section{International Journal of Engineering Applied Sciences and Technology, 2020 \\ Vol. 4, Issue 9, ISSN No. 2455-2143, Pages 372-376 \\ Published Online January 2020 in IJEAST (http://www.ijeast.com)}

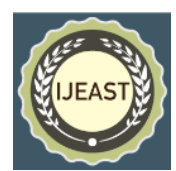

way receiver circuit can get the data from transmitter circuit is waiting for light waves from transmitter circuit. When receiver circuit receives data, output from receiver circuit is audio recorder and player kit that connected to receiver circuit will play audio based on the light signal received from the LED. It means different LED light waves will make audio recorder and player kit play different audio based on LED. Figure 6 displays the working of the final system.

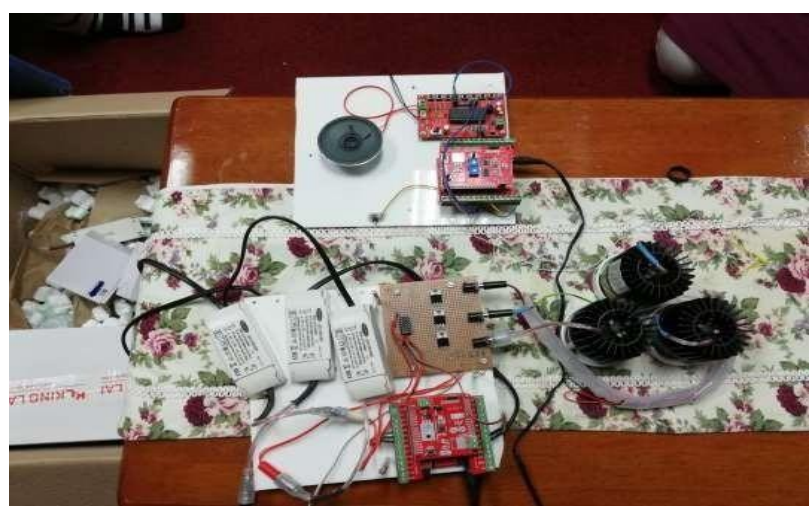

Figure 5: Final setup of the indoor navigation system

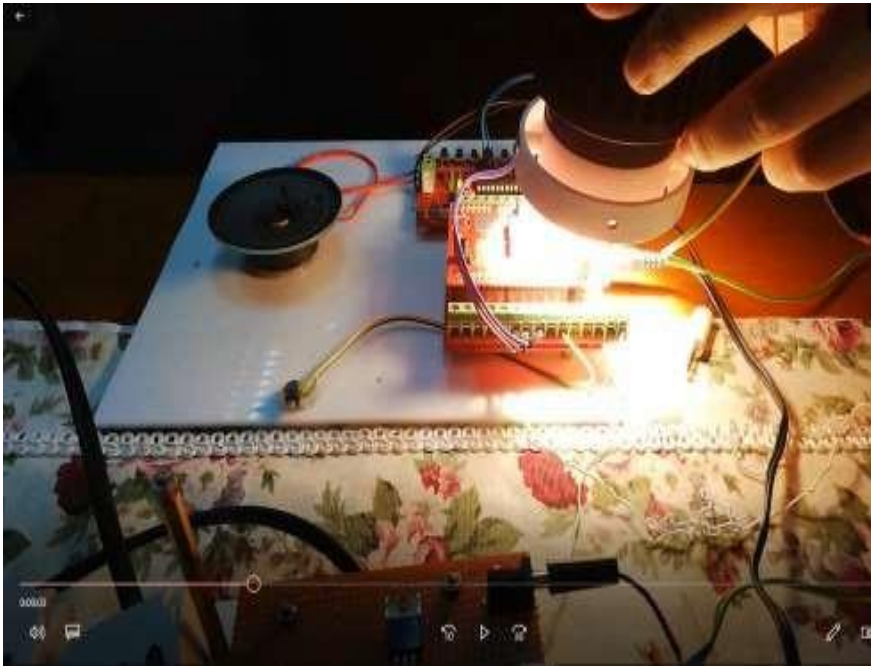

Figure 6. Functioning of the final setup

TABLE 1: RESULTS FOR LIFI BASED INDOOR NAVIGATION SYSTEM

\begin{tabular}{|l|l|l|}
\hline $\begin{array}{l}\text { SL } \\
\text { No }\end{array}$ & SWITCH & CONDITIONS \\
\hline 1 & SWITCH 1 & Caution, the stairs are ahead \\
\hline 2 & SWITCH 2 & Barrier on your right \\
\hline 3 & SWITCH 3 & The exit door on your left \\
\hline
\end{tabular}

\section{CONCLUSION}

Light Fidelity ( $\mathrm{Li}-\mathrm{Fi}$ ) is a technology for wireless communication between devices using light to transmit data and position. In its present state only light from light-emitting diodes (LEDs) lamp can be used for the transmission of visible light. The VLC system use in this paper for the indoor use where the impaired user can move without causing accident or having trouble moving with furniture and things around the room. The output of this paper is to help the visually impaired users to navigate conveniently when they move around and to able to transmit and receive direction correctly and well function for user to use. In order to make this paper work smoothly, it need to deal with changing weather conditions such as sun blazing. Moreover, light waves can easily be blocked and cannot penetrate thick walls like the radio waves can.

\section{ACKNOWLEDGEMENT}

We would like to thank the SNR management Trust and the Principal Dr. M. Paulraj for giving an opportunity to publish the paper work in the Journal. And we would like to thank external Project co-ordinator Dr.Norizan Mohamed Nawawi, Associate Professor, UniMap Perlis, Malaysia, for guiding and implementing the project in UniMap Perlis, Malaysia.

\section{REFERENCES}

[1] R. Bajaj, S. L. Ranaweera and D. P. Agrawal, et al (2002)"GPS: Location-Tracking Technology", IEEE Computer, Vol. 35, No. 4, (pp. 92-94).

[2] S. Hong, M. H. Lee, H. H. Chun, S. H. Kwon, and J. L. Speyer,et al (2005), "Observability of error states in GPS/INS integration," IEEE Trans. Veh. Technol., vol. 54, no. 2, (pp. 731-743)

[3] P. Enge, T. Walter, S. Pullen, C. Kee, Y. Chao, and Y. Tsai, et al (1996),"Wide area augmentation of the global positioning system," Proc. IEEE, vol. 84, (pp. 1063-1088).

[4]Anandakumar, et al (2014), "Energy Efficient Network Selection Using 802.16g Based Gsm Technology", Journal of Computer Science, vol. 10, no. 5, (pp. 745-754).

[5] Dr. Praveena Mary. S, et al (2017), "Design of wireless passive optical communication network based on fusion of fibre to the Home Architecture"vol.96 ,no.3,(pp.3851-3871). [6]Dr. Praveena Mary. S, Vennila, I., \& Vaishnavi , et al (2017), "Investigation of Passive Optical Network Based on QoS Issues in Wireless Fibre to the Home Architecture for Fault Identification and Detection", Wireless Communication, Vol 96,(pp.961-976).

[7] Dr. Praveena Mary, et al(2015), "An Effective Security Based Wireless Information System Based on Fusion Principal Component Analysis",vol 86, (pp.887-899).

[8] R Shanmughasundaram, S Prasanna Vadanan, Vivek Dharmarajan,et al(2018) "Li-Fi Based Automatic Traffic Signal Control for Emergency Vehicles", Advances in Electronics Computers and Communications (ICAECC)Second International Conference on, (pp. 1-5, 2018) 
[9] T. Koonen, J. Oh, K. Mekonnen, Z. Cao, E. Tangdiongga, et al (2018)"Indoor Optical Wireless Communication using Steered Pencil Beams", Journal of Lightwave Technology, vol. 34, no. 20, (pp. 4802-4809) [10] Rahul R. Sharma, Raunak, Akshay Sanganal, "Li-Fi Technology", International Journal of Computer Technology and Applications, vol. 5, no. 1, (pp. 150-154), ISSN 2229-6093.

[11].Roshini, H. Anandakumar, et al (2015), "Hierarchical cost effective leach for heterogeneous wireless sensor networks". 2015 International Conference on Advanced Computing and Communication Systems

[12] S. Rajagopal, R. Roberts, S.-K. Lim, et al(2002) "IEEE 802.15.7 visible light communication: Modulation schemes and dimming support", IEEE Communication Magazine, vol. 50, no. 3, (pp. 72-82) 